\title{
OPEN Identification and development of novel salt-responsive candidate gene based SSRs (cg-SSRs) and MIR gene based SSRs (mir-SSRs) in bread wheat (Triticum aestivum)
}

\author{
Geetika Mehta $^{1,3}$, Senthilkumar K. Muthusamy ${ }^{10^{1,2,3}}$, G. P. Singh ${ }^{1}$ \& Pradeep Sharma $\mathbb{1}^{1 凶}$
}

Salt stress adversely affects the global wheat production and productivity. To improve salinity tolerance of crops, identification of robust molecular markers is highly imperative for development of salt-tolerant cultivars to mimic yield losses under saline conditions. In this study, we mined 171 saltresponsive genes (including 10 miRNAs) from bread wheat genome using the sequence information of functionally validated salt-responsive rice genes. Salt-stress, tissue and developmental stage-specific expression analysis of RNA-seq datasets revealed the constitutive as well as the inductive response of salt-responsive genes in different tissues of wheat. Fifty-four genotypes were phenotyped for salt stress tolerance. The stress tolerance index of the genotypes ranged from 0.30 to 3.18. In order to understand the genetic diversity, candidate gene based SSRs (cg-SSRs) and MIR gene based SSRs (miR-SSRs) were mined from 171 members of salt-responsive genes of wheat and validated among the contrasting panels of 54 tolerant as well as susceptible wheat genotypes. Among 53 SSR markers screened, $10 \mathrm{cg}$-SSRs and $8 \mathrm{miR}$-SSRs were found to be polymorphic. Polymorphic information content between the wheat genotypes ranged from 0.07 to 0.67 , indicating the extant of wide genetic variation among the salt tolerant and susceptible genotypes at the DNA level. The genetic diversity analysis based on the allelic data grouped the wheat genotypes into three separate clusters of which single group encompassing most of the salt susceptible genotypes and two of them containing salt tolerance and moderately salt tolerance wheat genotypes were in congruence with penotypic data. Our study showed that both salt-responsive genes and miRNAs based SSRs were more diverse and can be effectively used for diversity analysis. This study reports the first extensive survey on genome-wide analysis, identification, development and validation of salt-responsive cg-SSRs and miR-SSRs in wheat. The information generated in the present study on genetic divergence among genotypes having a differential response to salt will help in the selection of suitable lines as parents for developing salt tolerant cultivars in wheat.

Wheat being staple food, its production is important for global food security. To meet out the food demand, the production of wheat needs to be increased up to $90-120 \%$ by 2050 . Globally, $430 \mathrm{M}$ ha of land is affected by salinity and an area of around $5.8 \times 10^{6} \mathrm{~km}^{2}$ of sodic soils have potential to develop into saline soils through the process of transient salinity ${ }^{1-3}$. These saline soils need to be utilized for food grain production to meet out the food demand of the growing population ${ }^{4}$. High yielding wheat cultivars grown under salt-affected soils were affected by physiological drought stress and ion toxicity, which resulted in yield reduction ${ }^{5-7}$. Salt stress also influences soil function, soil microbiome, pest infestation, etc. It is highly imperative to breed salt-resistant high yielding wheat cultivars that have the ability to thrive in saline soils ${ }^{8}$. Introgression of salt-stress responsive genes through marker-assisted and genomic selection has a potential impact on increasing the salt stress tolerance ability of high yielding bread wheat cultivars ${ }^{5,9}$. Moreover, availability of high quality draft sequence of wheat

${ }^{1}$ Division of Crop Improvement, ICAR-Indian Institute of Wheat and Barley Research, Agrasain Marg, PO BOX-158, Karnal, Haryana 132 001, India. 'Division of Crop Improvement, ICAR-Central Tuber Crops Research Institute, Thiruvananthapuram, India. ${ }^{3}$ These authors contributed equally: Geetika Mehta and Senthilkumar K. Muthusamy. ${ }^{\circledR}$ email: Pradeep.Sharma@icar.gov.in 
genome and other wheat genomic resources hastens the process of gene identification through comparative genomics approach and molecular marker development ${ }^{10-12}$. Therefore, functional characterization of genes and development of salt stress-responsive gene-based markers would be useful in breeding programs for improving salt tolerance in wheat ${ }^{7,13,14}$.

Plants employ special mechanisms including osmotic tolerance, ion exclusion tissue tolerance, redox equilibrium and others to combat salt stress ${ }^{6,15}$. Maintenance of low salt concentration in the cytoplasm was considered as a key component for plant cellular-tolerance towards salt stress ${ }^{5,16}$. Plants evolve a osmotic mechanism to compartmentalize the excess $\mathrm{Na}^{+}$and $\mathrm{Cl}^{-}$in vacuoles to maintain optimum salt concentrations in cytoplasm and organelles ${ }^{6,17,18}$. In Arabidopsis, mutants that failed in maintaining low cytosolic salt concentration were highly sensitive to salt stress ${ }^{19}$. Several salt-stress responsive genes with diverse cellular functions and miRNAs have been functionally validated for salt-stress tolerance in many crop plants including Arabidopsis and rice ${ }^{20-25}$. The $\mathrm{Na}^{+}$ ion exclusion capacity of bread wheat is higher than durum wheat, which increases the salt tolerance capacity of bread wheat than durum wheat. Introgression of TmNax2 locus from T. monococcum to durum wheat increased the salt tolerance ability of durum wheat and also increased the yield up to $25 \%$ greater than non-introgressed lines grown in saline soil ${ }^{26}$. High-affinity $\mathrm{K}^{+}$transporters (HKTs) play important role in regulation of $\mathrm{Na}^{+}$concentration in wheat ${ }^{6,7}$. Over-expression of TaNAC29 in Arabidopsis increased the salt-tolerance ability of transgenic Arabidopsis lines ${ }^{27}$. TaSRO1, a poly (ADP ribose) polymerase (PARP) domain containing protein regulate the reactive oxygen species homeostasis in wheat ${ }^{28}$. Over-expression of $\mathrm{TaAOC1}$, a allene oxide cyclase functioning in the $\alpha$-linolenic acid metabolism pathway, in both wheat and Arabidopsis increased the salt-tolerance ability of the transgenic lines ${ }^{29}$. Similiarly, transgenic wheat lines overexpressiong TaCHP, a zinc finger protein display enhanced salt tolerance ability than the wild type salinity-sensitive cultivar Jinan $177^{30}$. Transgenic Arabidopsis lines over-expressing the TaNIP wheat gene encoding for aquaporin protein showed increased tolerance for salt stress than wild type plants ${ }^{31}$. Overexpression of TaOPR1, a 12-oxo-phytodienoic acid reductases increase the salinity tolerance in transgenic wheat lines ${ }^{32}$. ClpATPase and HSP chaperones expression were increased under salt stress in bread wheat ${ }^{12,33}$. Over-expression of wheat TaSTRG in rice increased the salt-tolerance ability of transgenic rice lines ${ }^{34}$. Both, HKT gene based $\mathrm{Na}^{+}$exclusion pathway and the SRO gene mediated ROS homeostasis mechanism play major role in imparting salinity tolerance in wheat ${ }^{6,7}$. Conversely, several genes with diverse functions were known to regulate the salt stress mechanism in plants, minimal efforts have been made to identify their orthologs in wheat. Thus, the availability of high quality genomic resources in wheat eases the process of the identification of salt stress responsive genes ${ }^{10,11,14}$. Hence, in this study, we have used the genomic information of the functionally validated genes from wheat and other crop plants including rice and identified their salt stress respective putative orthologs in wheat. Salt-stress, tissue and developmental stage specific expression pattern were studied using the normalized wheat RNAseq datasets. Salt-stress responsive cgSSR and miR-SSR markers were developed and screened in a set of 54 wheat genotypes differing in salt tolerance.

\section{Results}

Phenotypic screening of the wheat germplasm for salt tolerance. In many plant species, salt tolerant genotypes evolved genetic mechanisms to avoid/exclude the accumulation of $\mathrm{Na}^{+}$and $\mathrm{Cl}^{-}$salts in the cytoplasm and also have ability to maintain high $\mathrm{K}^{+} / \mathrm{Na}^{+}$ratio in the cytoplasm ${ }^{7,15,35-37}$. In this study, the salt tolerance abilities of the 54 diverse wheat genotypes were estimated by studying the ability of genotypes to avoid/exclude the accumulation of $\mathrm{Na}^{+}$and $\mathrm{K}^{+}$salts, $\mathrm{K}^{+} / \mathrm{Na}^{+}$ratio maintenance and stress tolerance index (STI) under salt stress and control conditions ${ }^{35,38}$ (Fig. 1a,b; Supplementary Table S1a and Supplementary Table S1b). Among the 54 genotypes studied, the stress tolerance index value ranges from 0.30 to 3.18 , the maximum value was observed in the highly salt tolerant genotype KRL99 and the minimum in salt susceptible genotype HD4530 (Supplementary Table S1a). Interestingly, the genotypes having STI more than 2 comes under the category of most tolerant genotype i.e. KRL99, KRL35, KRL-3-4, KHARCHIA LOCAL, WH157, KHARCHIA65, KRL19 and KRL 1-4 displayed more than 2 STI and 27 genotypes having STI less than 1.00 comes under the category of salt susceptible (Supplementary Table S1a). The $\mathrm{K}^{+} / \mathrm{Na}^{+}$ratio in shoot under salt stress ranged from 3.9 to 32.44 with the maximum value in PBW343 and the minimum in HI1500 whereas in root the value ranged from 14.3 to 57.8 with the maximum value in RAJ4037 and the minimum in KRL213 (Supplementary Table S1b). To determine the salt tolerance index, a total of 54 genotypes were screened in two conditions (i.e. in control and stress for number of traits. On this basis, 54 genotypes were divided into three categories (i.e. tolerant, moderately tolerant and susceptible). The highest positive correlation of STI is found with SPAD values; therefore the tolerant genotypes had SPAD values more than 38.00 . The moderately tolerant genotypes had SPAD values ranging between 34.00 and 37.00 and the susceptible ones had values less than 34.00 . According to the Pearson correlation analysis, SPAD $(r=0.82)$, total dry weight $(r=0.99)$ and sodium content $(r=0.46)$ also showed positive significant correlation with salt tolerance index.

Identification of salt stress responsive and MIR-based genes in wheat. Salt- responsive genes have been well characterized in crop plants ${ }^{22,23,39,40}$ as shown in Supplementary Table S2 and Supplementary Table S3. Additionally, 70 genes were functionally characterized for salt-responsiveness in wheat (Supplementary Table S2). Using the protein sequences of the functionally validated salt-stress responsive genes, a BlastP search was performed against the wheat proteome database ${ }^{11}$ to identify the respective salt-responsive wheat orthologs (Supplementary Table S2 and Supplementary Table S4). Our analysis led to the identification of 171 salt-responsive candidate genes in wheat (Fig. 2, Supplementary Table S4 and Table 1). In order to gain an insight into the various functions that Tacg-SSR containing salt stress responsive candidate genes were grouped into six functional groups. Among the groups, 33\%, 24\%, 10\%, 6\%, $6 \%$ and $4 \%$ of the total salt stress responsive genes belongs to transcription factors, signaling and kinase, transporter, biosynthesis, DNA/RNA modification 
a)

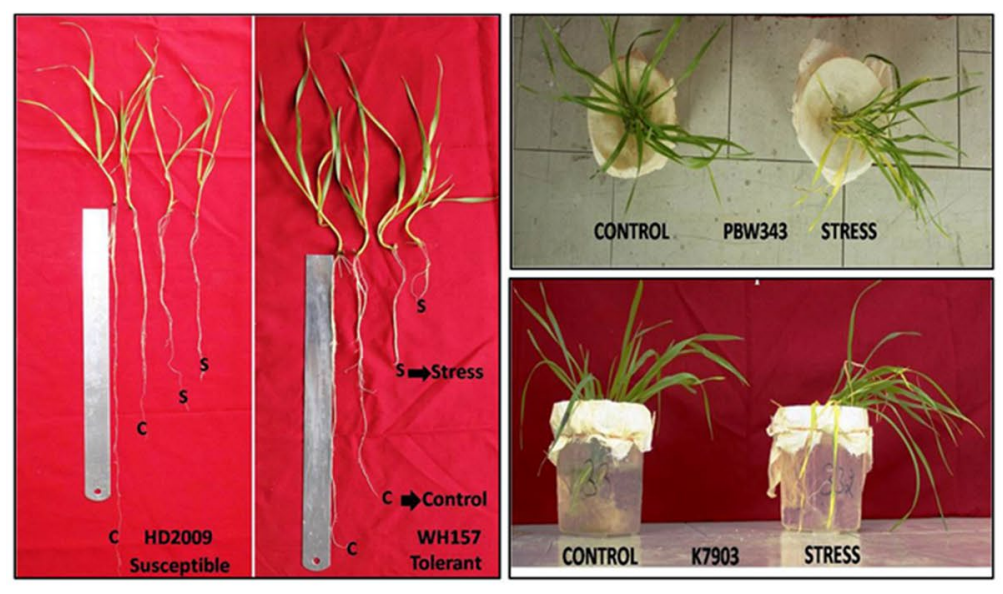

b)

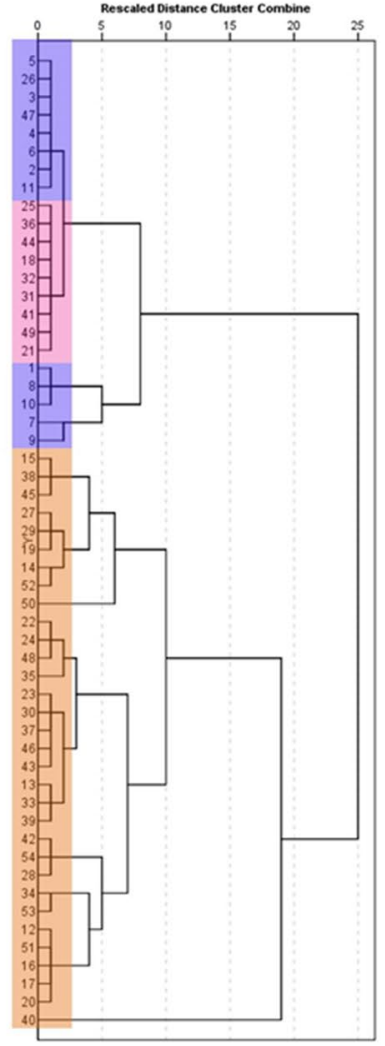

Figure 1. The phenotypic evaluation for salinity tolerance. (A) Effect of salt treatment on 54 diverse wheat genotypes under hydroponics conditions, (B) dengrogram showing phenotypic variability relationship between 54 wheat genotypes based upon phenotypic data. The cluster is made on the basis of all positive correlation of these traits i.e. total dry weight (TDW), chlorophyll content (SPAD) and sodium content in roots (NA) with salt tolerance index (STI). This dendrogram divides into two major cluster i.e. cluster I and cluster II. Cluster I contains total of 22 genotypes and all the genotypes comes under tolerant and moderately tolerant group. Cluster II contains all susceptible genotypes.

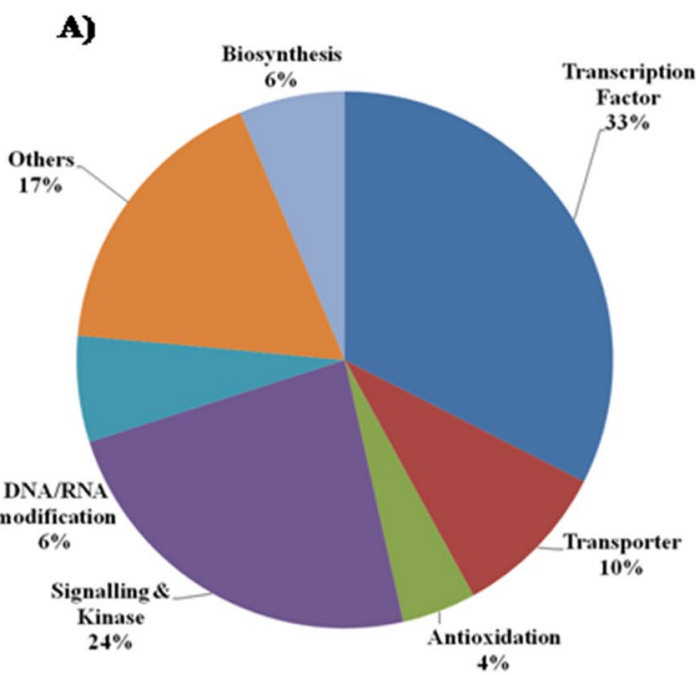

B)

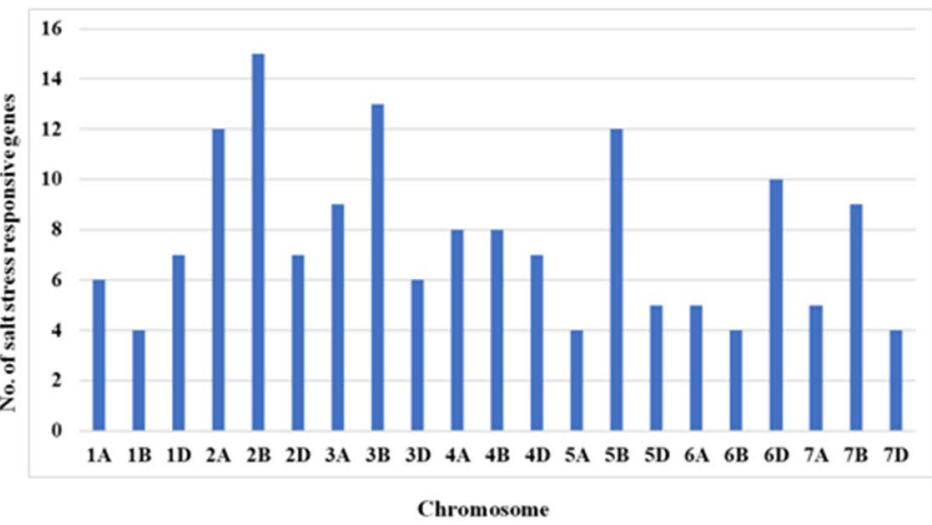

Figure 2. Frequency and distribution of salt stress responsive genes in wheat (A) Functional classes of identified salt responsive genes in wheat (B) Chromosomal distribution of salt stress responsive genes in wheat. Details of chromosomal location and scaffold regions of salt stress responsive genes were given in Supplementary Table S4. 


\begin{tabular}{|l|l|l|l|}
\hline Gene & Ensembl plants gene ID & Chromosomal location & Chromosome survey sequence \\
\hline Tamir160a & EPITAET00000001376 & 5D & 5D:138155564:138155659 \\
\hline Tamir169a & EPITAET00000007608 & 5D & IWGSC_CSS_5DL_scaff_4542798:2336:2470 \\
\hline Tamir169e & EPITAET00000000922 & 5D & 5D:107380642:107380789 \\
\hline Tamir169k & EPITAET00000008126 & 5B & 5B:190176930:190177077 \\
\hline Tamir169m & EPITAET00000007781 & 5D & 5D:107380659:107380784 \\
\hline Tamir169n & EPITAET00000000696 & 7B & 7B:111090146:111090267 \\
\hline Tamir171a & EPITAET00000007580 & 6B & IWGSC_CSS_6BS_scaff_3031431:1976:2081 \\
\hline Tamir171b & EPITAET00000003067 & 1A & IWGSC_CSS_1AL_scaff_3909165:20040:20143 \\
\hline Tamir172a & EPITAET00000008820 & 1A & 1A:226362546:226362702 \\
\hline Tamir172d & EPITAET00000000231 & 6A & 6A:203905904:203906014 \\
\hline
\end{tabular}

Table 1. Salt stress responsive $M I R$ genes in Wheat.

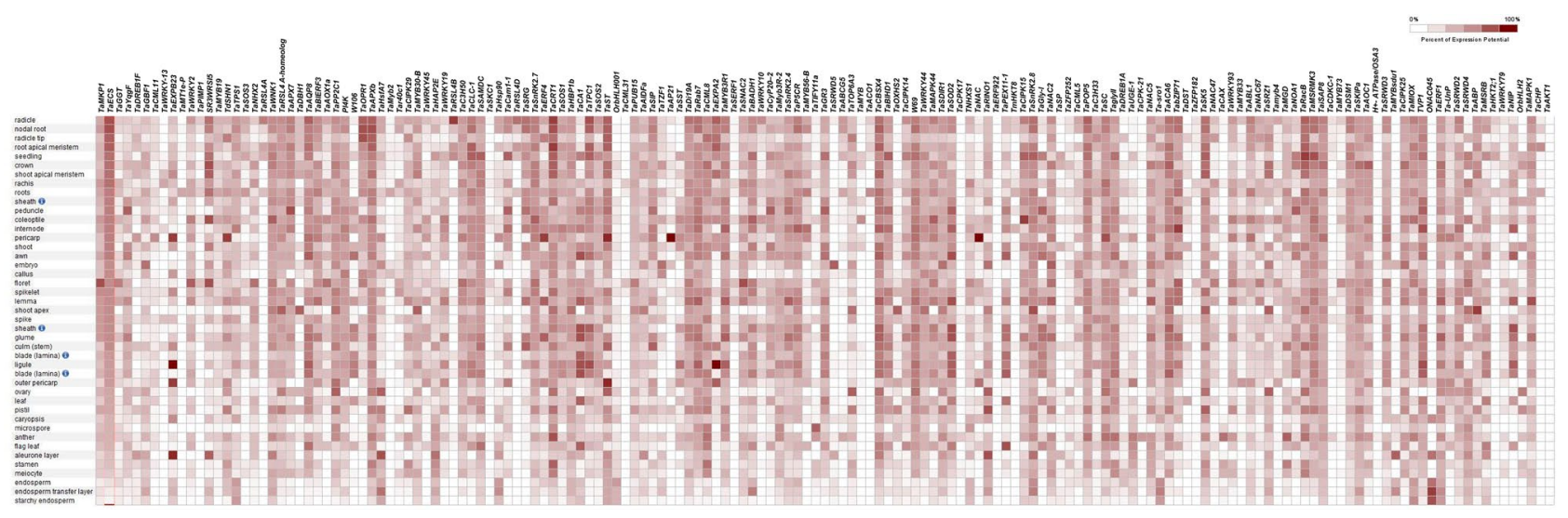

Figure 3. RNA-seq based tissue-specific expression profiles of salt stress responsive genes in wheat. (A) Expression profile. (B) Developmental stage-specific expression profile. The expression datasets were normalized and presented as heat maps using meta-analysis tool. The intensity of color represents the percent expression profile of the genes as described in the legend bar.

and antioxidation, respectively (Fig. 2A and Supplementary Table S4). The chromosomal location and scaffold details of the identified salt stress responsive genes were retrieved from the wheat genome database ${ }^{11}$. Our analysis showed that salt responsive genes are widely distributed in all the 21 chromosomes of bread wheat, with the maximum of 15 genes located in $2 \mathrm{~B}$, followed by 13 genes in $3 \mathrm{~B}$, Twelve genes were located in each of two chromosomes, $2 \mathrm{~A}$ and $5 \mathrm{~B}$. Ten genes were located in $6 \mathrm{D}$ while nine genes were located in each of two chromosomes, $3 \mathrm{~A}$ and $7 \mathrm{~B}$. Eight genes were located in each of two chromosomes, 4A and 4B. Seven genes were located in each of three chromosomes, 1D, 2D and 4D. Six genes were located in each of two chromosomes, $1 \mathrm{~A}$ and $3 \mathrm{D}$, while five genes were located in each of three chromosomes, 5D, 6A and 7A. Four genes were located in each of four chromosomes, 1B, 5A, 6B and 7D (Fig. 2B and Supplementary Table S4). The chromosomal location of one gene was not assigned in the wheat genome database (Supplementary Table S4). The cellular localization of the saltresponsive genes was predicted using WoLF PSORT ${ }^{41}$ and TargetP 1.1 server $^{42}$ (Supplementary Table S4). The nucleotide sequences of the salt-stress responsive $M I R$ genes were used in a query against the wheat small RNA database that identified the respective salt-responsive wheat orthologs (Table 1 and Supplementary Table S2). The initial analysis further led to the identification of $24 M I R$ genes, 14 duplicated $M I R$ genes sequences were removed subsequently using Clustal Omega tool ${ }^{43}$. Finally, we identified 10 salt stress-responsive MIR genes in wheat (Table 1). Around 988 genes were under the regulation of 10 MIR genes. The details of the target transcripts of MIR genes are given in Supplementary Table S5.

Spatio-temporal expression analysis of salt responsive genes in wheat. Tissue-specific and stage-specific expression pattern of identified 161 wheat salt-responsive genes were studied using the normalized wheat mRNA-seq expression datasets developed by the International Wheat Genome Sequencing Consortium (IWGSC) through the Genevestigator database ${ }^{44,45}$. In total, the expression of salt responsive genes were studied in the 43 tissues and ten developmental stages (Figs. 3, 4). Our analysis showed that all 161 salt stress responsive genes (except TaAKT1) were expressed in at least one tissue/development stage (Figs. 3, 4). In particular, the genes like TaMKP1, TaECS, TaGGT, TaYqgF, TaGBF1, TaCML11, TaEXPB23, TaWRKY2, SR3WRSI5, TaMYB19, TdSHN1, TaTPS1, TaNHX2, TaWNK1, TaRSL4 A-homeolog, TaAPX7, TaAQP8, TaBIERF3, TaAOX1a, TaPP2C1, PI4K, TaAPXb, TaHsfA7, TaCIPK29, TaMYB30-B, TaHAP2E, TaWRKY19, TaC3H50, TaCLC-1, TaSAMDC, 


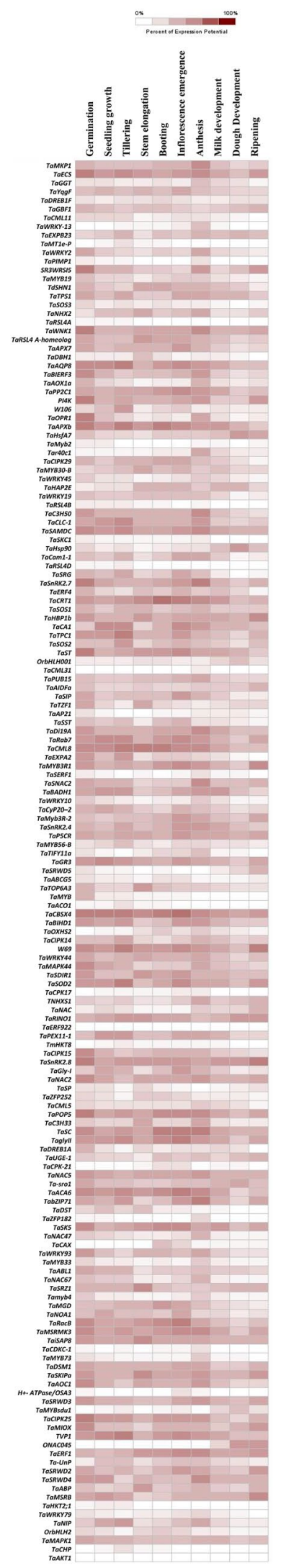

Figure 4. RNA-seq based developmental-specific expression profiles of salt stress responsive genes in wheat. The expression datasets were normalized and presented as heat maps using meta-analysis tool. The intensity of color represents the percent expression profile of the genes as described in the legend bar. 


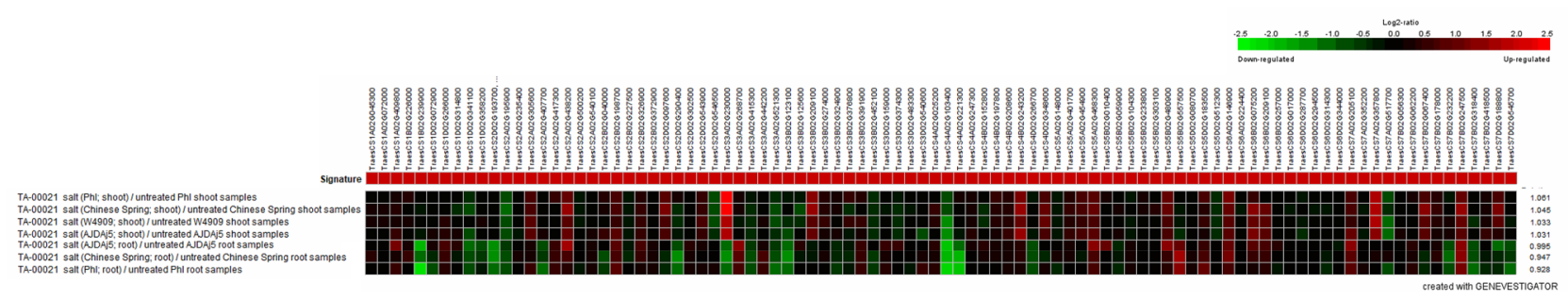

Figure 5. RNA-seq based salt stress-specific expression profiles of salt stress responsive genes in wheat. The expression datasets were normalized and presented as heat maps using meta-analysis tool. The intensity of color represents the percent expression profile of the genes as described in the legend bar.

TaSRG, TaSnRK2.7, TaERF4, TaCRT1, TaSOS1, TaHBP1b, TaTPC1, TaSOS2, TaST, TaPUB15, TaAIDFa, TaSIP, TaDi19A, TaRab7, TaCML8, TaMYB3R1, TaSNAC2, TaBADH1, TaMyb3R-2, TaSnRK2.4, TaP5CR, TaCBSX4, TaCIPK14, W69, TaWRKY44, TaMAPK44, TaSDIR1, TaSOD2, TNHXS1, TaNAC, TaRINO1, TaPEX11-1, TaCIPK15, TaSnRK2.8, TaNAC2, TaCML5, TaPOP5, TaSC, TaglyII, TaNAC5, Ta-sro1, TaACA6, TabZIP71, TaSK5, TaNAC47, TaWRKY93, TaABL1, TaSRZ1, Tamyb4, TaMGD, TaNOA1, TaRacB, TaMSRMK3, TaiSAP8, TaDSM1, TaSKIPa, TaAOC1, TaSRWD3, TaCIPK25, TaMIOX, TVP1, TaERF1, Ta-UnP, TaSRWD2, TaABP, TaMSRB, TaWRKY79, TaNIP and TaMAPK1 were expressed in most of the tissues and in all ten developmental stages, as well (Figs. 3, 4). Nevertheless, there were significant differences in their level of expression (Figs. 3, 4). Expression of TaEXPB23, TaHsfA7, TaRINO1 and TaMYBsdu1 were higher in the aleurone layer. The expression of TaGBF1, TaHsp90, TaTZF1 and TaSRWD5 were higher in embryo tissue whereas ONAC045 and Tasro1 expression were higher in endosperm tissue. The expression of TabZIP71 and TVP1 genes were higher in internodes. SR3WRSI5, TaWNK1 and TaCIPK15 expression were higher in coleoptile tissues. The expression of TaEXPB23, TaST, TdSHN1, TaERF4, TaAP21 and TaNAC were higher in pericarp tissues. TaWRKY-13, TaC3H33, TabZIP71 and TaTPS1 expression were higher in spikelet tissue. TaSnRK2.8, TaSK5, TaSRZ1 and TaABP (Fig. 3) were higher in root tissues. The expression of TaECS, SR3WRSI5, TaWNK1, PI4K, TaOPR1, TaAPXb, TaSnRK2.7,TaST, TaPOP5, TaSK5, TaRacB, TaMSRMK3, TaAOC1 and TaCIPK25 were increased during germination stage (Fig. 4). TVP1, TaACA6, TaglyII, TaCBSX4, W69, TaSOD2, TaCML8, TaTPC1, TaAPXb and TaAQP8 expression were higher at tillering stage (Fig. 4). The expression of TaSK5, TaACA6, TaSC, TaglyII, TaPOP5, TaCBSX4, TaCML8, TaCRT1 and TaAPXb were higher in booting stage (Fig. 4). TabZIP71, TaSC, TaSnRK2.7, TaWNK1, TaMKP1 and TaECS expression were higher at anthesis stage (Fig. 4). The expression of TaECS, TaSnRK2.8, W69, TaMYB3R1, PI4K and SR3WRSI5 were higher in ripening stage (Fig. 4).

Expression analysis of salt stress responsive genes in wheat. The salt stress-responsive expression patterns of the identified genes were studied using normalized wheat genome array datasets ${ }^{33,44,46}$ Out of 171 genes, 96 genes have the genome array expression information under salt stress conditions (Fig. 5). Shoot and root-tissue specific expression of the identified genes during tillering stage were studied using the normalized salt-stress specific expression datasets developed by Mott and Wang ${ }^{46}$ through the Genevestigator tool (Fig. 5). The expression of 11 genes viz., TaAOX1a, TaHAP2E, TaNAC2, TaNAC5, TabZIP71, TaWRKY93, TaNAC67, TaSRZ1, TaMYBsdu1, TaMSRB and TaCLC-1 were upregulated, whereas the expression of seven genes viz., TaTPS1, TaWNK1, TaST, TaPUB15, TaBADH1, TaABCG5 and ONAC045 were downregulated both in shoot and root tissues during tillering stage under salt stress (Fig. 5). Ten genes viz., TaAPX7, TaCam1-1, TaSST, TaSOD2, TaPEX11-1, TaGly-I, TaMIOX, Ta-UnP, TaNIP and TaERF4 were upregulated, whereas the expression of two genes (viz., TaCRT1 and TaTZF1) were both down-regulated in shoot tissues during the tillering stage under salt stress (Fig. 5). In root tissues, five genes viz., TaGBF1, TaBIERF3, TaTPC1, OrbHLH001 and Ta-sro1 were up-regulated whereas, the expression of thirteen genes viz., TaMT1e-P, TaWRKY2, TaSOS3, TaRSL4D, TaAQP8, TaOPR1, TaSRG, TaSIP, TaACO1, TaRINO1, TaABP, TaHKT2;1 and TaCHP were down-regulated during the tillering stage under salt stress (Fig. 5). Interestingly, the expression of TaCA1 was up-regulated in shoot tissues and down-regulated in the root tissue during tillering stage under salt stress (Fig. 5).

qPCR expression analysis of salt responsive genes. The magnitude of expression of eight randomly selected salt-stress responsive genes were studied in the root tissues of fourteen days old seedling under salt stress. TaDSM1 and TaCML11 expression was downregulated in both the genotypes (Fig. 6). Interestingly, the expression of five genes viz., TabZIP71, TaSRZ1, TaMyb2, TaTPC1 and TaSAMDC were upregulated in salt-tolerant genotype Kharchia65, whereas, all the five genes were downregulated in the salt-susceptible genotype HD 2009 (Fig. 6). The expression pattern of selected salt-stress responsive genes is largely in correspondence with the array datasets (Fig. 6). The primer details used for the expression studies is given in Supplementary Table S6.

Identification and validation of salt-responsive cg-SSRs and mir-SSRs in wheat. Salt stressresponsive candidate gene-based SSRs (cg-SSR) and MIR gene based SSRs (miR-SSRs) were mined from the identified wheat salt stress responsive genes using the BatchPrimer3 tool ${ }^{47,48}$. Out of 171 genes (including 10 MIR genes) screened, 115 genes yielded a total of 264 SSR loci (69\%) (Fig. 7A,B, Supplementary Table S2, Supplementary Table S3 and Supplementary Table S7). List of salt-responsive genes harboring SSR motifs with their respective ensemble plants LOC ID, their functionality, motif repeatability and SSRs location were detailed 


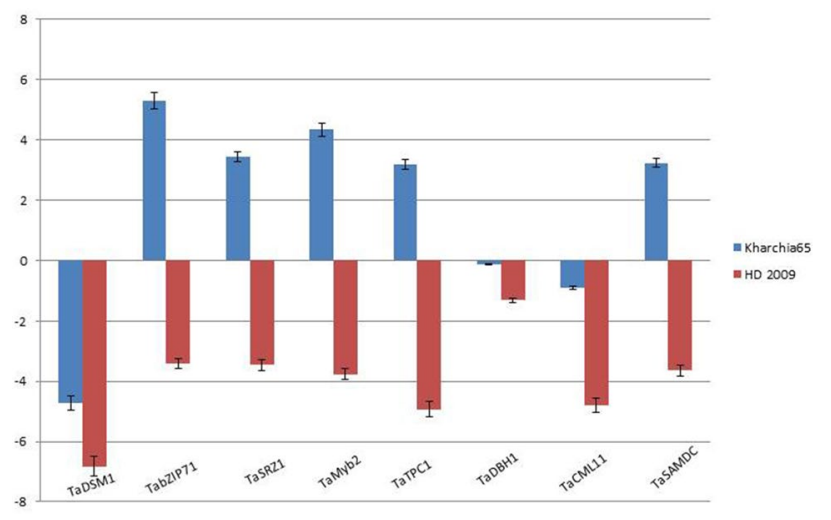

Figure 6. Expression analysis of salt responsive genes through qPCR.

A)

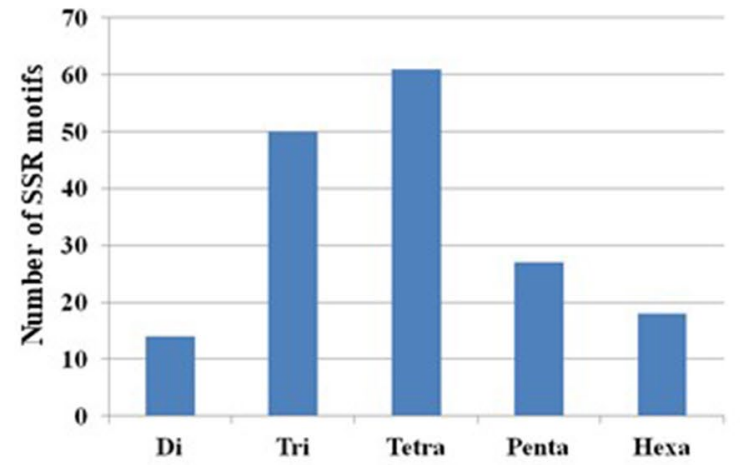

B)

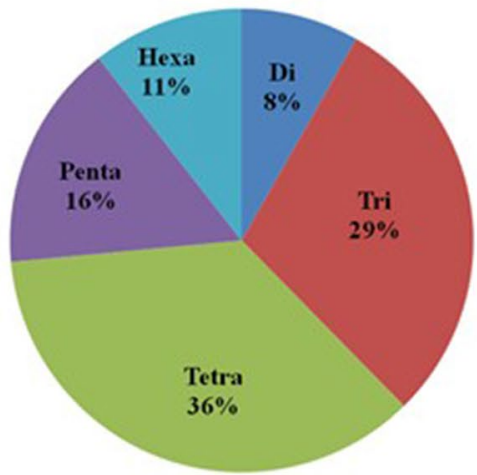

C)

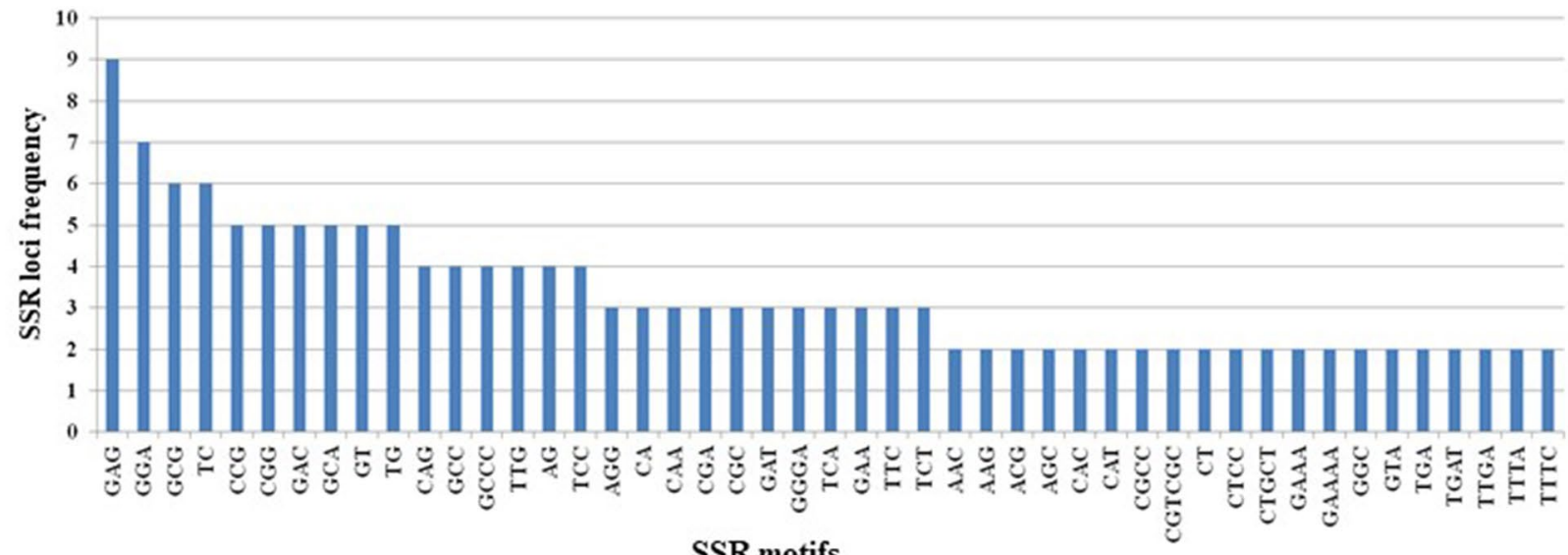

SSR motifs

Figure 7. Frequency and distribution of salt stress responsive cg-SSRs and MIR-SSRs in wheat. (A) Number of different SSR motifs found, (B) Percentage of different SSR loci present in salt stress responsive genes (C) SSR loci frequency in salt stress responsive genes (only $\geq 2$ times repeated SSR loci shown in the figure, For completed list refer Supplementary Table 3.

in Supplementary Table S7. In rice, tri-nucleotide repeats were the largest motif found in salt-responsive genes ${ }^{22}$. In our study, the tetra-nucleotide repeats were the largest motif, comprising about $36 \%$ followed by the tri-nucleotide repeat motifs comprising $29 \%$ whereas, di-, penta- and hexa-nucleotides formed small share having $8 \%$, $16 \%$ and $11 \%$ respectively (Fig. $7 \mathrm{~A}, \mathrm{~B}$ ). The number of repetitions of a motif varied from 3 to 19 , among which, a motif with four reiterations (a motif repeated four times) were higher in frequency followed by three, five, six and seven repetition (Fig. 7C; Supplementary Table S7). The salt-responsive SSRs were present on all the 21 chromosomes of wheat (Supplementary Table S7). Conversely, the distribution of SSRs was not equal among the 
chromosomes, For example, the maximum frequency (14\%) of salt stress-responsive gene-based SSR loci were found on chromosome $2 \mathrm{~B}$, whereas the least $(0.1 \%)$ was found on chromosome $1 \mathrm{~B}$ (Supplementary Table S7). Chromosome 1A, 3B, 4A, 4B, 5B, 5D, 6A, 6D and 7A were found to contain more than 5\% SSR marker loci (Supplementary Table S7). Out of 264 SSR loci, we randomly selected 53 SSR loci, including 10 MIR gene based SSRs for wet lab validation (Supplementary Table S7).

Allele scoring and data analysis. To test the amplification and polymorphism of the identified genicSSRs, 53 SSRs chosen randomly were synthesized for validation in a set of 54 wheat genotypes. Based on a polymorphism survey, 18 polymorphic SSR (10 cg-SSRs and 8 miR-SSRs; Table 2$)$ were identified and used for generating polymorphism profiles of the selected panel of wheat genotypes. These primers generated a total of 49 alleles across the wheat genotypes analysed (Table 2). The multiallelic SSR markers were run on 6\% PAGE gel electrophoresis. The banding pattern of Tacg-SSR21, TamiR160a-SSR, TamiR169k-SSR and TamiR169l-SSR in 54 diverse wheat genotypes as shown in Fig. 8A-D, respectively. The lowest and highest amplicon size was $143 \mathrm{bp}$ and $238 \mathrm{bp}$ amplified with Tacg-SSR37 and Tacg-SSR17 markers, respectively (Table 2). The PIC value denotes the allelic diversity among the 54 genotypes. The miR-SSRs (TamiR-172d-SSR) exhibited the lowest PIC value (0.07) while the highest PIC value (0.67) obtained with the Tacg-SSR19 (Table 2) with the mean value of 0.44. Out of these 18 polymorphic SSRs, Tacg-SSR18 and TamiR160a-SSR displayed highest variation (5 alleles/ marker), followed by TamiR169m a-SSR (4 alleles/marker) whereas Tacg-SSR1, Tacg-SSR11, Tacg-SSR21, TacgSSR23, Tacg-SSR24, Tacg-SSR37, TamiR 169i-SSR, TamiR172a-SSR, TamiR 171a-SSR and TamiR 172d-SSR displayed 2 allele/marker on PAGE gel electrophoresis (Table 2).

Analysis of genetic diversity. The binary data generated from 18 polymorphic SSR markers profiling of 54 contrasting wheat genotypes were used to study the genetic diversity by dissimilarity analysis and factorial analysis through cluster analysis (Table 2). The binary data deduced from their respective SSRs profiles divided all the 54 wheat genotypes into three major clusters (Fig. 9). The salt tolerant wheat genotypes were found to be more diverse than salt susceptible genotypes. The majority of salt tolerant wheat genotypes/genetic stocks were grouped into a single cluster (Cluster I) including KRL210, KRL213, KRL99, KRL-3-4, KRL35, WH157, KRL1-4 and Kharchia65, which indicated the influence of pedigree and source on clustering pattern (Fig. 9) A majority of the lines derived from Kharchia65 local landrace have been utilized for salt wheat breeding programs in India. The smallest cluster (cluster II) contained salt susceptible genotypes HS240, RAJ3765, RAJ4210, PBW590, RAJ4079 and RAJ4037 except for HD2967 and WH1080 which are moderately tolerant to salinity. Cluster III consisted of twenty wheat genotypes representing moderately salt tolerance. These included NW1014, UP2338, PBW550, PBW343, GW322, DBW17, DBW90, HD2285, HD2932, NIAW34, DW1, K7903, HUW468, UP2382, VL616, MP4010, HUW510 and HD2808. In our study, genetic diversity analysis using salt stress-responsive gene-based cg-SSRs and miR-SSRs clearly distinguished the wheat genotypes into different groups based on their sensitivity to salinity (Fig. 9).

\section{Discussion}

Salt stress is one of the serious abiotic stress that limits the crop yield, hence it is highly imperative to understand the molecular mechanisms of salt stress tolerance which would aid efforts to support/architect plant salt tolerance. It exerts a inimical effect on wheat by affecting crucial metabolic process including the process of photosynthesis, protein synthesis and lipid metabolism ${ }^{6,7,49,50}$. The effect of climate change will exacerbate the severity of salt stress in the future ${ }^{51,52}$. High yielding salt resistance cultivars need to be bred and introduced in the salt affected marginal lands to meet out the demand of the growing population ${ }^{52,53}$. Identification of salt stressresponsive genes based on SSRs will aid in breeding of salt stress tolerant high yielding wheat cultivars ${ }^{3,7,8,54,55}$. Although several studies reported the characterization of salinity tolerance using SSRs ${ }^{56,57}$, this work epitomized the genome identification of both salt-stress responsive gene-based cgSSRs and miR-SSR markers and its role in genetic diversity with respect to salinity tolerance in wheat.

Salt tolerance is a complex response involving a diverse set of genes having wide functional roles, i.e. transcription factors, transporters, ion channels, signalling and kinase, DNA/RNA modification, etc. ${ }^{16,21,58}$. Several genes have been functionally validated for salt tolerance in plants (Supplementary Table S2 and Supplementary Table S3). Minimal efforts have been made to identify their orthologs in wheat. In this study, 171 (including 10 $M I R$ genes) salt-stress responsive wheat orthologs were identified using the sequence information of functionally validated rice salt-stress responsive genes (Supplementary Table S2, Table 1, Supplementary Table S3 and Supplementary Table S4). The identified wheat salt stress-responsive genes had diverse functional roles and were grouped into six functional groups, viz transcription factors, signaling and kinase, transporter, biosynthesis, DNA/RNA modification and antioxidation, representing 33\%, 24\%, $10 \%, 6 \%, 6 \%$ and $4 \%$, respectively, owing to their diverse functional significance in wheat (Fig. 2A and Supplementary Table S4). The RNA-seq and arraybased expression analysis showed spatiotemporal transcriptional regulation and salt stress responsive expression, indicating their diverse role in plant growth and development (Figs. 3, 4, 5, 6).

Recent studies had shown the presence of microsatellite motifs in salt-stress responsive candidate genes in rice $^{22,59}$ and MIR genes ${ }^{23,60}$. However, very little information on experimental evidence for the occurrence of SSRs in miRNA precursors is available. The advantages of these markers over other marker types are high reproducibility and sufficient polymorphism, which have caused plant researchers to develop these marker systems ${ }^{23}$. Moreover, these markers (cg-SSR and miR-SSR) can be utilized finding marker trait association in genetic mapping studies. In rice, $180 \mathrm{cg}$-SSRs motifs were identified from 106 salt stress-responsive genes and genetic diversity analysis using 19 SSRs motifs differentiated the contrasting rice genotypes into tolerant and susceptible based on their sensitivity to salinity ${ }^{22}$. Chen et al. ${ }^{60}$ mined SSRs from $\sim 9000$ premature miRNAs representing 87 species 


\begin{tabular}{|c|c|c|c|c|c|c|c|}
\hline S. no. & Marker & Primer sequence & Expected alleles & Observed alleles & No of alleles & TM & PIC \\
\hline 1 & Tacg-SSR1 & $\begin{array}{l}\text { F 5'GAAGATGAAGAGTCGGAT } \\
\text { GA 3' } \\
\text { R 5'GTACTCCTCCTTGCTGAT } \\
\text { CTC 3' }\end{array}$ & 186 & $181-186$ & 2 & 60 & 0.302 \\
\hline 2 & Tacg-SSR8 & $\begin{array}{l}\text { F 5'GTCTCGTCTCCCCGCCTC } \\
\text { A 3' } \\
\text { R 5'ACAGTTCCGACACCACAA 3' }\end{array}$ & 187 & $160-190$ & 3 & 60 & 0.535 \\
\hline 3 & Tacg-SSR11 & $\begin{array}{l}\text { F 5'GCTGTAGTTGTGCTCCTT } \\
\text { TTA 3' } \\
\text { R 5'ACAAGGCATAGCTCATAC } \\
\text { TCC 3' }\end{array}$ & 146 & $150-155$ & 2 & 60 & 0.253 \\
\hline 4 & Tacg-SSR17 & $\begin{array}{l}\text { F 5'AACAACCTCCAACGCTCT 3' } \\
\text { R 5'GTCGAAGGACCGGAAGAT 3' }\end{array}$ & 238 & $230-400$ & 3 & 62 & 0.655 \\
\hline 5 & Tacg-SSR18 & $\begin{array}{l}\text { F 5'CCAACTTGTTTGGGACTA } \\
\text { AAG 3' } \\
\text { R 5'AAACGGCACCTCTACATA } \\
\text { ACT 3' } \\
\end{array}$ & 151 & $140-490$ & 5 & 61.6 & 0.412 \\
\hline 6 & Tacg-SSR19 & $\begin{array}{l}\text { F 5'TACCCCAAAGTGAGTTCT } \\
\text { ACA 3' } \\
\text { R 5'CACCAGCTTTAGGTGCAT 3' }\end{array}$ & 284 & $280-300$ & 3 & 60 & 0.666 \\
\hline 7 & Tacg-SSR21 & $\begin{array}{l}\text { F 5'CTAGCTTCGTTTGTCTGT } \\
\text { TGT 3' } \\
\text { R 5'GATGTAGTTGGCGAGGAG 3' }\end{array}$ & 148 & $136-150$ & 2 & 61.6 & 0.370 \\
\hline 8 & Tacg-SSR23 & $\begin{array}{l}\text { F 5'GGTCTCTAACCATGTATC } \\
\text { GTG 3' } \\
\text { R 5'AAACTAGTAAGCATGCAC } \\
\text { TCG 3' } \\
\end{array}$ & 172 & $169-190$ & 2 & 56 & 0.499 \\
\hline 9 & Tacg-SSR24 & $\begin{array}{l}\text { F 5'GCATCAGGTTCTGTATCA } \\
\text { ATC 3' } \\
\text { R 5'ATCAGGAGCCAGTAGAAA } \\
\text { ATC 3' }\end{array}$ & 184 & $190-210$ & 2 & 56 & 0.50 \\
\hline 10 & Tacg-SSR37 & $\begin{array}{l}\text { F 5'AGCATTGACCCCAAATAT } \\
\text { C 3' } \\
\text { R 5'TCGAAAGGGTATAGGCTT } \\
\text { AGT 3' }\end{array}$ & 143 & $150-200$ & 2 & 62 & 0.491 \\
\hline 11 & TamiR 160a-SSR & $\begin{array}{l}\text { F 5'GAGGTGAAAACAATGGGA } \\
\text { TA 3' } \\
\text { R 5'CCAGGAATCTAAAGCAAC } \\
\text { C 3' }\end{array}$ & 174 & $160-189$ & 5 & 61.6 & 0.662 \\
\hline 12 & TamiR 169i-SSR & $\begin{array}{l}\text { F 5'ACTCCTACAAAACATGCA } \\
\text { GAG 3' } \\
\text { R 5'GTGACTCTTATCGTTCAT } \\
\text { GCT 3' } \\
\end{array}$ & 151 & $175-195$ & 2 & 61.6 & 0.499 \\
\hline 13 & TamiR 172a-SSR & $\begin{array}{l}\text { F 5'ATGTATAGGACAAAGGGA } \\
\text { AGC 3' } \\
\text { R 5'ATCAAGATTCACATCCAT } \\
\text { CC 3' }\end{array}$ & 160 & $150-180$ & 2 & 61.6 & 0.444 \\
\hline 14 & TamiR 169k-SSR & $\begin{array}{l}\text { F 5'GTGTGTGTGGAGAGAGAG } \\
\text { AGA 3' } \\
\text { R 5'TATATCCACAGGCAAGTC } \\
\text { ATC 3' }\end{array}$ & 149 & $152-163$ & 3 & 60 & 0.652 \\
\hline 15 & TamiR $169 \mathrm{~m}-\mathrm{SSR}$ & $\begin{array}{l}\text { F 5'TATATCCACAGGCAAGTC } \\
\text { ATC 3' } \\
\text { R 5'TGCCATGTAGAGAGAGAG } \\
\text { AGA 3' }\end{array}$ & 152 & $150-300$ & 4 & 62.6 & 0.558 \\
\hline 16 & TamiR 171a-SSR & $\begin{array}{l}\text { F 5'CGACGAGCAGTGAGATAT } \\
\text { AAG 3' } \\
\text { R 5'GTCCGTCGTAAACCTAAC } \\
\text { ATA 3' }\end{array}$ & 171 & $169-174$ & 2 & 60 & 0.460 \\
\hline 17 & TamiR 172d-SSR & $\begin{array}{l}\text { F 5'TATTAAGTGCCTCTGCCA } \\
\text { GT 3' } \\
\text { R 5'GAGATTATTGTGGTACGT } \\
\text { GGA 3' }\end{array}$ & 158 & $160-190$ & 2 & 56 & 0.071 \\
\hline 18 & TamiR 169l-SSR & $\begin{array}{l}\text { F 5'TCTCACTAGACCCCTCTC } \\
\text { TTC 3' } \\
\text { R 5'GTTTGAGGTGCTACAAAT } \\
\text { GG 3' }\end{array}$ & 145 & $137-145$ & 3 & 56 & 0.650 \\
\hline
\end{tabular}

Table 2. Details of polymorphic Tacg-SSRs and TamiR-SSRs used in this study.

and showed the presence of mono-nucleotide, di-nucleotide tri-, tetra-, penta- and hexa- nucleotide repeats in MIR genes. Taking into account the potential significant of gene based cg-SSRs and miR-SSRs, we mined SSRs in the identified salt-stress responsive genes (including MIR genes) of wheat and analyzed their allelic banding 
a)

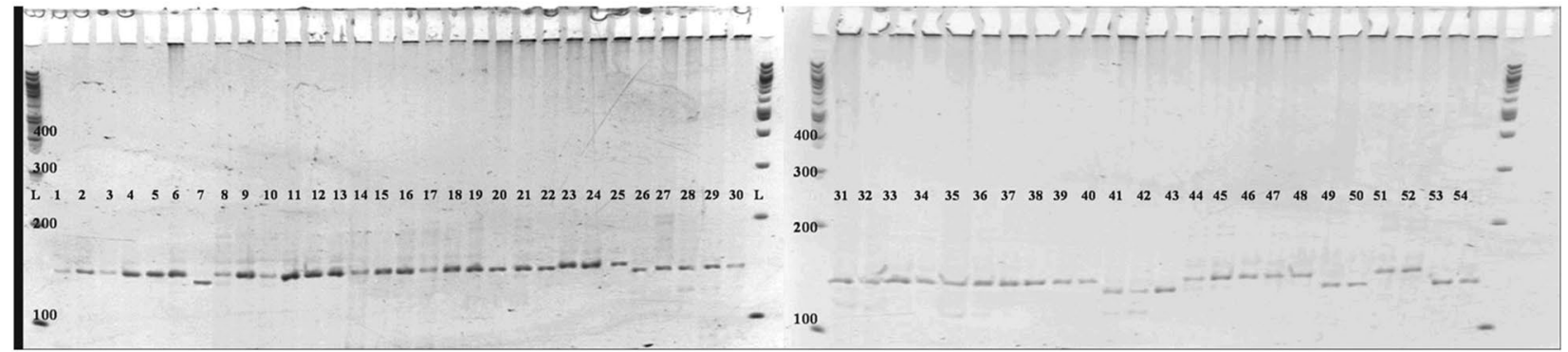

b)

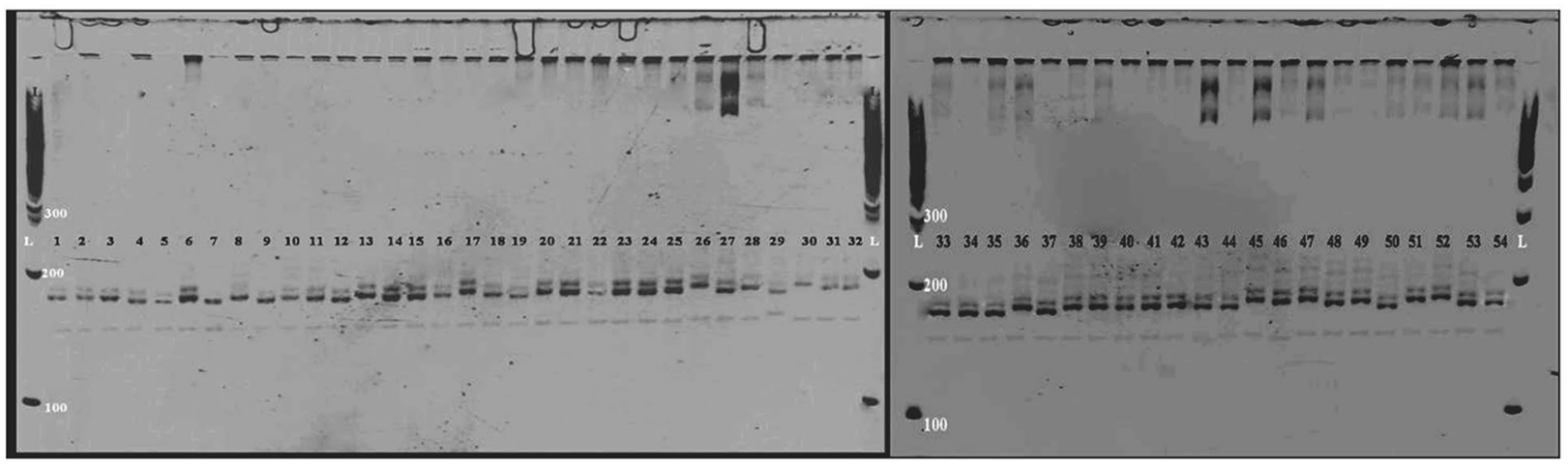

c)

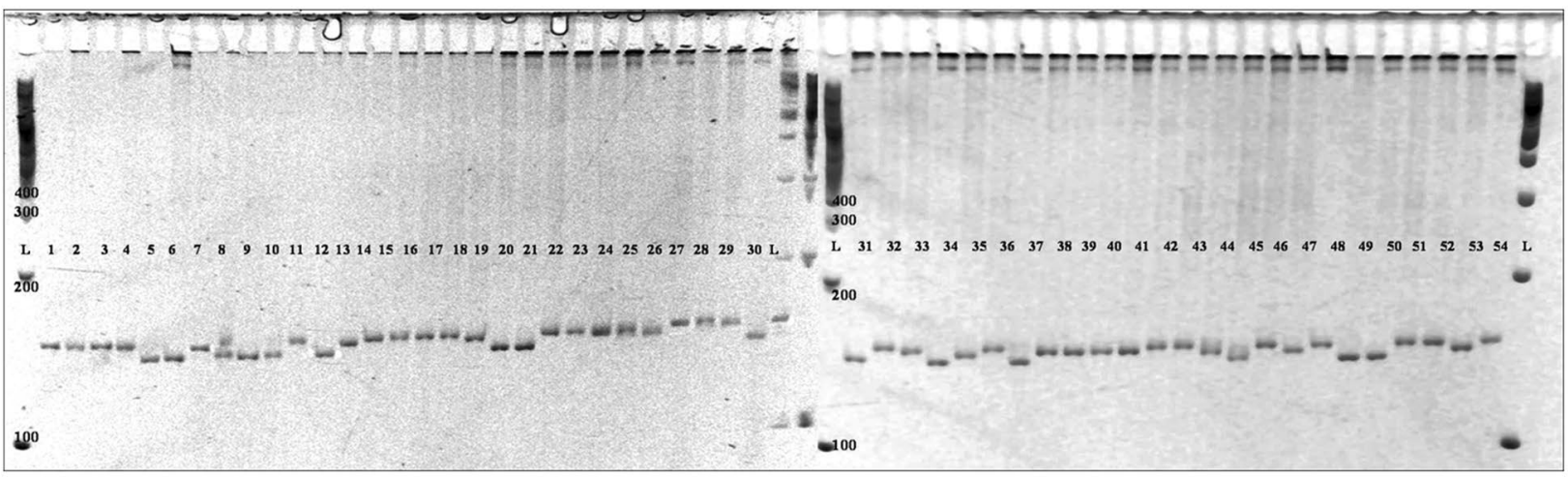

d)

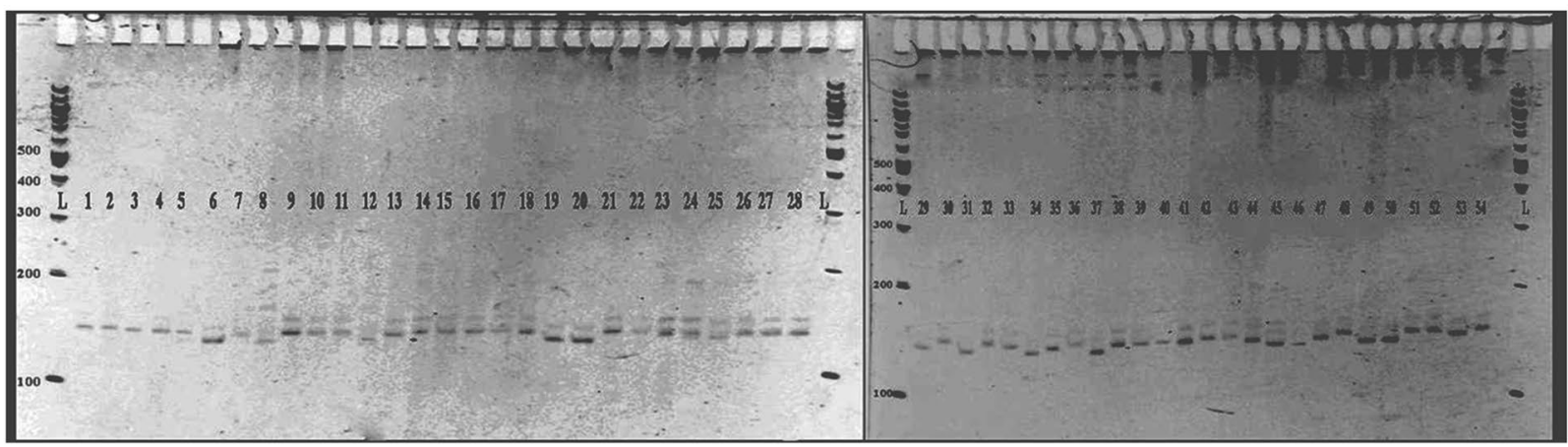

Figure 8. Amplification of genomic DNA from different wheat genotypes with (A) Tacg-SSR11, (B) TamiR160a, (C) TamiR-169k and (D) TamiR-169l. L represents 100 bp ladder. 


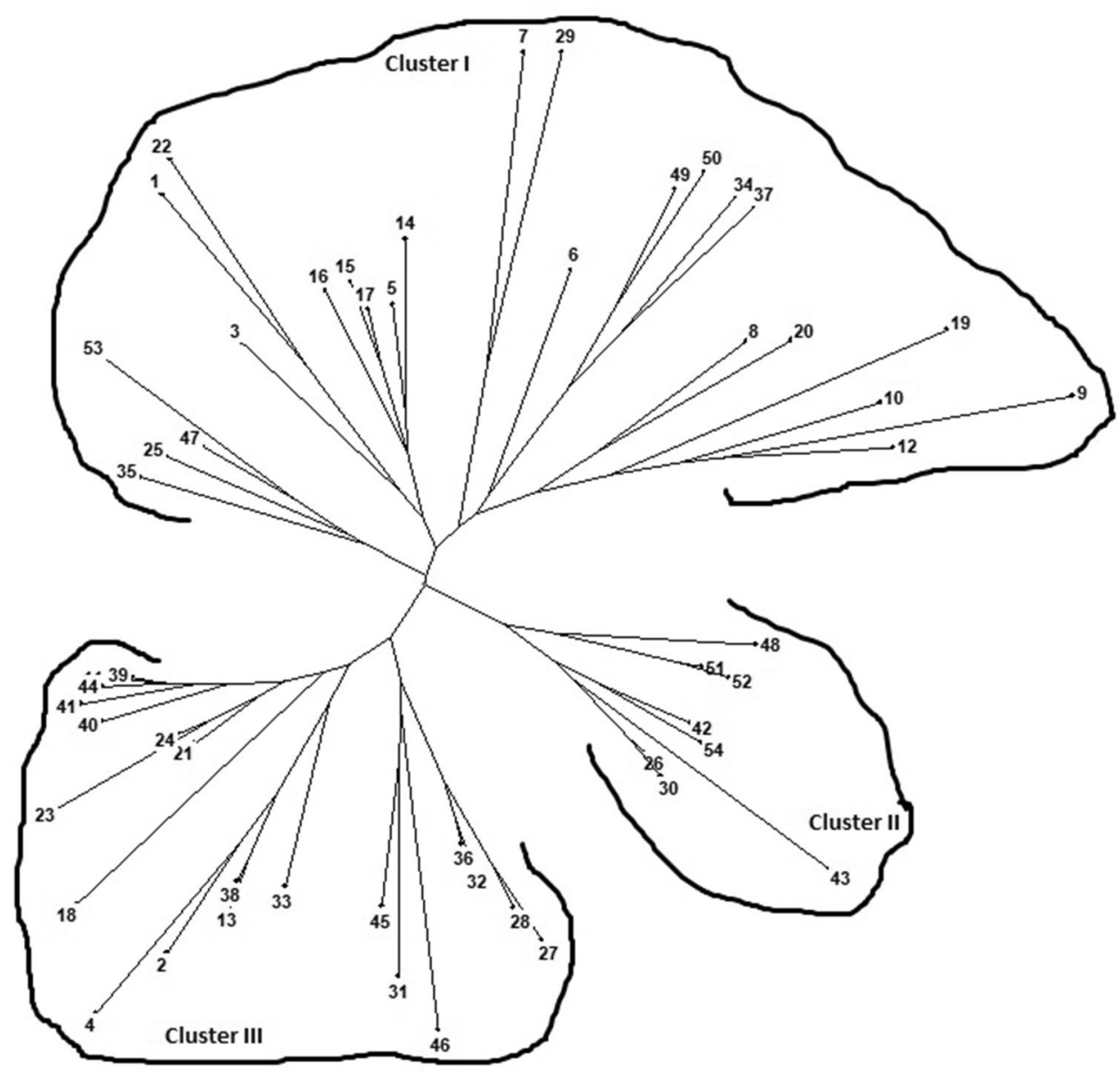

Figure 9. Dendrogram generated from UPGMA analysis based on salt stress responsive cg-SSRs and MIR-SSRs segregation data of 54 wheat genotypes. The details of the genotypes given in the Supplementary Table 1.

pattern on the differential response of the genotypes to salt stress. Out of 168 genes screened, 118 genes yielded a total of 264 SSR loci representing 69\% of salt stress responsive genes (Fig. 7A,B and Supplementary Table S7). Tetra-nucleotide repeats were the most abundant repeats followed by the tri-nucleotide repeats as compared to di-, penta- and hexa-nucleotide repeats (Fig. 7A,B and Supplementary Table S7). In rice, 18 cg-SSRs displayed polymorphism and their banding pattern differentiated the contrasting rice genotypes into tolerant and susceptible group based on their sensitivity to salinity ${ }^{23}$. Similarly, miR172b-SSR, a MIR gene based SSR marker, was able to differentiate rice germplasm into a tolerant and susceptible group based on their sensitivity to salinity ${ }^{23}$. In our study, $10 \mathrm{cg}$-SSRs and $8 \mathrm{miR}-S S R s$ (out of $10 \mathrm{miR}-\mathrm{SSRs}$ ) were shown to be polymorphic and able to differentiate the contrasting wheat genotypes having differential responses to salt and the availability of significant genetic diversity among salt tolerant and susceptible genotypes (Table 2 and Figs. 8A-D, Fig. 9).

$\mathrm{Ma}$ et al. ${ }^{61}$ revealed $24.6 \%$ polymorphism in the developed genomic-SSR in common buckwheat was lower than the genomic-SSR polymorphism (26.7\%) reported by the Konishi et al. ${ }^{62}$. In our study, the PIC value ranged from 0.07 to 0.62 and the dendrogram generated using the binary score of these allelic data grouped the 54 contrasting wheat genotypes for salt tolerance into three distinct clusters, of which one single cluster contained all salt susceptible genotypes and two of them contained tolerant wheat genotypes (Fig. 9). The salt tolerant wheat genotypes were found to be more diverse than salt susceptible genotypes. The smallest cluster (cluster II) also contained salt susceptible genotypes HS240, HD2967, RAJ3765, RAJ4210, PBW590, RAJ4037, and RAJ4079 except for HD2967 and WH1080, which are moderately salt tolerance. Cluster III consists of twenty wheat genotypes representing moderate salt tolerance. This includes NW1014, UP2338, PBW550, PBW343, GW322, DBW17, DBW90, HD2285, HD2932, NIAW34, DW1, K7903, HUW468, UP2382, VL616, MP4010, HUW510 and HD2808. The majority of salt tolerant wheat genotypes/genetic stocks were grouped into a single cluster (Cluster I) KRL210, KRL213, KRL99, KRL-3-4, KRL35, WH157, KRL-1-4 and Kharchia65 indicated the effect of pedigree and the source on grouping pattern (Fig. 9). In our study, phenotypic data and genetic diversity analysis using salt stress-responsive gene-based cg-SSRs and miR-SSRs clearly distinguished the wheat genotypes into different groups based on salt sensitivity (Fig. 9). Thus, the 18 gene-based SSRs developed in this study may be used to distinguish wheat genotypes based on their susceptibility to salt stress (Table 2 and Fig. 9). 


\section{Conclusion}

This study conducted an extensive genome-wide analysis, identified salt responsive-genes, and mined and validated gene-based cg-SSR and miR-SSRs, proving these methods as remarkable tools to distinguish wheat genotypes based on sensitivity to salt stress. Spatio-temporal expression regulation of salt-stress responsive genes indicated a distinct role of these genes in wheat growth and development. The cg-SSRs and miR-SSRs developed here can provide unique genomic resources for a wheat breeding program with delivering novel alleles to develop high yielding salt tolerance varieties/breeding lines. Hence, these markers have high potential of linkage and can be explored for gene pyramiding in wheat breeding programme for salt tolerance trait.

\section{Materials and methods}

Phenotypic screening of the wheat germplasm for salt tolerance. A diverse set of 54 wheat (Triticum aestivum) genotypes differing in salt tolerance ability was collected from the germplasm unit of ICARIndian Institute of Wheat and Barley Research (IIWBR), Karnal (Supplementary Tables S1a). These genotypes were phenotyped for salt tolerance in two conditions, i.e. control and stress for salt tolerance at the seedling stage ${ }^{35,38}$. The wheat seeds were surface sterilized with $\mathrm{HgCl}_{2}(0.1 \%)$ and grown in hydroponic conditions with full strength Hoagland solution. After 14 days, $\mathrm{NaCl}$ treatment was given for 7 days to 14 days old seedling in two conditions, i.e. control $(2 \mathrm{mM})$ and stress $(117 \mathrm{mM})$ in photoperiod of $14 \mathrm{~h}$ light and $10 \mathrm{~h}$ dark at $25 \pm 2{ }^{\circ} \mathrm{C}$. The Hogland solution was changed at every 2 nd day to reduce the chance of contamination. The chlorophyll content was measured by chlorophyll meter (SPAD-502 Plus, Konica Minolta) and chlorophyll flourescence (Fv/Fm) was measured by chlorophyll fluorescence meter (Model OS30P+, opti-sciences, Inc. USA) from the mid rib of the 3rd leaf at 3rd day of salt treatment and last day of the experiment. For $\mathrm{Na}^{+}$and $\mathrm{K}^{+}$estimation, the salt stress treated plant root and shoot samples were collected from each genotype. The tissues were oven-dried at $65^{\circ} \mathrm{C}$ for 5 days. From the dried samples of root and shoot, $70 \mathrm{mg}$ of each sample were taken and digested in diacid having $\mathrm{HNO}_{3}: \mathrm{HCLO}_{4}(9: 4)$. The $\mathrm{Na}^{+}$and $\mathrm{K}^{+}$concentration were measured from root and shoot samples by using microprocessor flame photometer ${ }^{35}$. The salt stress tolerance index was also calculated as described by Fernandez ${ }^{38,63}$.

$$
\text { Stress tolerance index }-\mathrm{Yp} * \mathrm{Ys} / \overline{\mathrm{Y}} \mathrm{p}^{2}
$$

whereas Yp, performance of genotypes under normal condition. Ys, performance of genotypes under stress condition. $\bar{Y} p^{2}$, mean performance of all genotypes under normal condition.

Identification of salt stress responsive genes in wheat. Several genes have been functionally validated for salt stress tolerance in rice and wheat (Supplementary Table S2). We downloaded the protein sequences of the functionally validated salt stress responsive genes from rice genome TIGR and NCBI databases (Supplementary Table S2) $)^{33,64}$. These protein sequences were used as a query against the wheat proteome database to identify the respective wheat orthologs ${ }^{11}$. The chromosomal location and scaffold details of the genes were retrieved from the wheat genome database ${ }^{11}$. The online tools, WoLF PSORT ${ }^{41}$ and TargetP 1.1 serve $^{42}$ were used to predict the sub-cellular localization of the identified salt-responsive wheat proteins.

Identification of salt responsive MIR genes and their gene targets in wheat. Many miRNAs genes were functionally validated for salt stress tolerance (Supplementary Table S3). We have used known miRNAs as a query against the wheat genome and miRBase databases and identified the salt-responsive TaMIR gene family members for further analysis ${ }^{12,24}$. The duplicated TaMIR sequences were removed by Clustal Omega ${ }^{43}$. The matured miRNA sequences targeting the salt-responsive genes were predicted using psRNATarget server with default parameters ${ }^{65,66}$.

Digital expression analysis. Tissue and developmental stage-specific expression pattern of identified wheat salt-responsive genes were studied by analysing the normalized IWGSC high quality mRNA-seq expression datasets of wheat ${ }^{11}$ using Genevestigator and exVIP database ${ }^{12,44,67}$. Wheat genome array datasets developed by Mott and Wang ${ }^{46}$ was used to study the salt-stress specific expression using the Genevestigator tool ${ }^{44}$.

qPCR expression analysis of salt responsive genes. To validate the array expression eight saltresponsive DEGs were randomly selected. The seeds of two bread wheat varieties Kharchia65 and HD 2009 were surface sterilized with $\mathrm{HgCl}_{2}(0.1 \%)$ and grown in hydroponic conditions with full strength Hoagland solution. After fourteen days, the $\mathrm{NaCl}$ treatment $(117 \mathrm{mM})$ was given to the wheat seedlings for $3 \mathrm{~h}$ and samples were collected for expression analysis. Total RNA was extracted from the root tissues using the RNA isolation kit (Qiagen). DNA was removed using the RNase-free DNase and RNA was purified using Qiagen RNeasy column. The cDNA was synthesised through the Superscript ${ }^{\oplus}$ III First Strand cDNA Synthesis kit as per manufacturer's instructions. The qPCR was done in a reaction volume of $10 \mu \mathrm{l}$ containing $3 \mu \mathrm{l}$ of cDNA, $5 \mu \mathrm{l}$ of $2 \times$ SYBR Green Master Mix (Thermo Scientific) and $1 \mu \mathrm{l}$ each of forward and reverse primer as per the manufacturers instructions. Actin gene was used as intenal reference gene for normalization. Expression analysis were performed using three biological replicates and relative expression level was computed using comparative $2^{-\Delta \Delta \mathrm{Ct}} \operatorname{method}^{68,69}$. The details of primers used in the qRT-PCR study was given in Supplementary Table S6.

SSR mining and primer designing. The identified salt stress-responsive genes genomic sequences were used to mine candidate gene-based (cg-SSRs) and miRNA SSRs (miR-SSRs) in wheat. The BatchPrimer3 tool was used for mining SSRs. The primers were designed using the BatchPrimer3 tool from the flanking sequences of the identified microsatellite repeats ${ }^{47,48}$. We included di-, tri-, tetra-, peta- and hexa- nucleotide repeats; rep- 
etition of motifs less than three times were excluded. The following parameters were used for primer design: primer length 18-24 bp, melting temperature (Tm) $58-62{ }^{\circ} \mathrm{C}$, amplicon size $100-250 \mathrm{bp}$ and GC content $45-60 \%$. Details of microsatellite repeats, SSR primers, melting temperature (Tm), amplicons size are given in Supplementary Table S7.

Plant materials and genomic DNA extraction. A diverse panel of 54 T. aestivum cultivars with contrasting salt-tolerance were used in this study. These genotypes were grown at an optimum temperature of $22 \pm 2{ }^{\circ} \mathrm{C}$ under a $16 \mathrm{~h} / 8 \mathrm{~h} \mathrm{light/dark}$ cycle in plant tissue culture room. Details of wheat genotypes are given in Supplementary Table S1a. Fresh leaf sample was collected from 54 different wheat genotypes at the seedling stage. DNA was isolated by CTAB method with little modification ${ }^{70}$. Leaf tissue $(\sim 1 \mathrm{~g})$ was ground to fine powder using liquid nitrogen. Fine powder was transferred to a $50 \mathrm{ml}$ Falcon tube containing $5 \mathrm{ml}$ of pre-warmed CTAB DNA extraction buffer (2.0\% CTAB (w/v); $0.2 \mathrm{M}$ Tris-Cl, pH 8; $0.02 \mathrm{M}$ of EDTA, pH 8; $1.4 \mathrm{M} \mathrm{NaCl})$. Samples were incubated at $65^{\circ} \mathrm{C}$ for $1 \mathrm{~h}$. An equal volume of chloroform-isoamyl alcohol (24:1) was added to each sample at room temperature. The solution was mixed by inverting the tubes and centrifuged at $12,000 \mathrm{rpm}$ for $10 \mathrm{~min}$ at room temperature. The aqueous phase was removed and transfered to an Eppendorf tube, 2/3rd volume of chilled isopropanol was then added. Genomic DNA was precipitated by centrifugation at $12,000 \mathrm{rpm}$ for $15 \mathrm{~min}$ at $4{ }^{\circ} \mathrm{C}$. Pellet was air dried and dissolved in $500 \mu \mathrm{l}$ autoclaved double distilled $\mathrm{H}_{2} \mathrm{O}$. RNase-A was added to each sample to remove RNA contamination. The quality and concentration of gDNA were checked using $0.8 \%$ agarose gel electrophoresis (Bio-Rad, USA).

PCR amplification and PAGE. A total of 53 SSRs comprising $43 \mathrm{cg}$-SSRs and $10 \mathrm{miR}-\mathrm{SSR}$ was designed to observe the polymorphism patterns in 54 genotypes of wheat (Supplementary Table S1a and Supplementary Table S7). All the SSR primers were amplified with gDNA isolated from 54 different genotypes of wheat as a template using a C1000 Thermal Cycler (Bio-Rad, USA). Each $25 \mu \mathrm{l}$ PCR reaction contained $100 \mathrm{ng}$ gDNA as a template, $1 \times$ Taq DNA polymerase buffer, $2 \mathrm{mM} \mathrm{MgCl}$, $0.2 \mathrm{mM}$ dNTPs mix, $1 \mathrm{U}$ of Taq DNA polymerase, and $0.5 \mathrm{pM}$ each of the forward and reverse primers (New England Biolabs, UK Ltd.). The PCR was optimized at an initial denaturation step of $95^{\circ} \mathrm{C}(4 \mathrm{~min})$, followed by 35 cycles of $94{ }^{\circ} \mathrm{C}(30 \mathrm{~s}), 55^{\circ} \mathrm{C}(30 \mathrm{~s}), 72^{\circ} \mathrm{C}(30 \mathrm{~s})$ and a final extension step of $72{ }^{\circ} \mathrm{C}(10 \mathrm{~min})$. The SSR PCR products were resolved in a vertical $6 \%$ non denaturing polyacrylamide gel electrophoresis (PAGE) system with 1X TAE (Tris acetate EDTA) buffer (pH 8.0). The gel was stained with ethidium bromide solution and visualized in a gel documentation system (C.B.S Scientific Co., Del Mar, CA). The composition of polyacrylamide gel included: acrylamide:bisacrylamide (29:1) (\% w/v), ammonium persulfate $(10 \% \mathrm{w} / \mathrm{v})$ and TEMED. The electrophoresis unit, glass plates, combs and spacers, gelsealing tape, micropipette, petroleum jelly and syringe were cleaned with $70 \%$ ethanol. The fragment size of each locus was determined by a 100 bp standard size marker (NEB). Results were confirmed by two replicate assays.

Data analysis. The cg-SSRs and miR-SSRs based marker profiles amongst the 54 genotypes of wheat were scored for the presence (1) or absence (0) of the amplicons and a binary matrix was generated. Polymorphism information content (PIC) value of each primer pairs was calculated with the help of the formula: PIC $=1-\sum \mathrm{pi}^{2}$, where $\mathrm{pi}$ is equal to the frequency of the ith allele of a particular locus ${ }^{71}$. Genetic distance among the genotypes based on allelic data and Euclidean distance matrix were estimated using neighbour joining method in DARwin software v5.0.158

Received: 26 October 2018; Accepted: 3 December 2020

Published online: 26 January 2021

\section{References}

1. Rengasamy, P. World salinization with emphasis on Australia. J. Exp. Bot. 57, 1017-1023 (2006).

2. Vengosh, A. Salinization and saline environments. Environmental geochemistry. In Treatise on Geochemistry Vol. 11 (eds Holland, H. D. \& Turekian, K. K.) 325-378 (Academic Press, Cambridge, 2013).

3. Munns, R. Genes and salt tolerance: bringing them together. New Phytol. 167, 645-663 (2005).

4. Tilman, D., Balzer, C., Hill, J. \& Befort, B. L. Global food demand and the sustainable intensification of agriculture. Proc. Natl. Acad. Sci. USA 108, 20260-20264 (2011).

5. Munns, R., James, R. A. \& Läuchli, A. Approaches to increasing the salt tolerance of wheat and other cereals. J. Exp. Bot. 57, 1025-1043 (2006).

6. Munns, R. \& Gilliham, M. Salinity tolerance of crops: what is the cost?. New Phytol. 208, 668-673 (2015).

7. Wang, M. \& Xia, G. The landscape of molecular mechanisms for salt tolerance in wheat. Crop J. 6, 42-47 (2018).

8. Agarwal, P. K., Shukla, P. S., Gupta, K. \& Jha, B. Bioengineering for salinity tolerance in plants: state of the art. Mol. Biotechnol. 54, 102-123 (2013).

9. James, R. A., Blake, C., Byrt, C. S. \& Munns, R. Major genes for Na ${ }^{+}$exclusion, Nax1 and Nax2 (wheat HKT1;4 and HKT1;5), decrease $\mathrm{Na}^{+}$accumulation in bread wheat leaves under saline and waterlogged conditions. J. Exp. Bot. 62, 2939-2947 (2011)

10. Wang, M., Wang, S. \& Xia, G. From genome to gene: a new epoch for wheat research?. Trends Plant Sci. 20, 380-387 (2015).

11. IWGSC. International Wheat Genome SequencingConsortium (IWGSC). Shifting the limits in wheat research and breeding using a fully annotated reference genome. Science 361, eaar7191 (2018).

12. Muthusamy, S. K., Dalal, M., Chinnusamy, V. \& Bansal, K. C. Genome-wide identification and analysis of biotic and abiotic stress regulation of small heat shock protein (HSP20) family genes in bread wheat. J. Plant Physiol. 211, 100-113 (2017).

13. Song, Q. J. et al. Development and mapping of microsatellite (SSR) markers in wheat. Theor. Appl. Genet. 110, 550-560 (2005).

14. Adamski, N. M. et al. A roadmap for gene functional characterisation in crops with large genomes: lessons from polyploid wheat. eLife 9, e55646 (2020).

15. Chinnusamy, V., Jagendorf, A. \& Zhu, J.-K. Understanding and improving salt tolerance in plants. Crop Sci. 45, 437-448 (2005). 
16. Hanin, M., Ebel, C., Ngom, M., Laplaze, L. \& Masmoudi, K. New insights on plant salt tolerance mechanisms and their potential use for breeding. Front. Plant Sci. 7, 1787 (2016).

17. Isayenkov, S. V. \& Maathuis, F. J. M. Plant salinity stress: many unanswered questions remain. Front. Plant Sci. 10, 80 (2019).

18. Shabala, S. Learning from halophytes: physiological basis and strategies to improve abiotic stress tolerance in crops. Ann. Bot. 112, 1209-1221 (2013).

19. Møller, I. S. \& Tester, M. Salinity tolerance of Arabidopsis: a good model for cereals?. Trends Plant Sci. 12, 534-540 (2007).

20. Golldack, D., Li, C., Mohan, H. \& Probst, N. Tolerance to drought and salt stress in plants: unraveling the signaling networks. Front. Plant Sci. 5, 151 (2014).

21. Gupta, B., Huang, B., Gupta, B. \& Huang, B. Mechanism of salinity tolerance in plants: physiological, biochemical, and molecular characterization. Int. J. Genomics 4, 109-126 (2014).

22. Molla, K. A., Debnath, A. B., Ganie, S. A. \& Mondal, T. K. Identification and analysis of novel salt responsive candidate gene based SSRs (cgSSRs) from rice (Oryza sativa L.). BMC Plant Biol. 15, 1-11 (2015).

23. Mondal, T. K. \& Ganie, S. A. Identification and characterization of salt responsive miRNA-SSR markers in rice (Oryza sativa). Gene 535, 204-209 (2014).

24. Katiyar, A. et al. Identification of novel drought-responsive microRNAs and trans-acting siRNAs from Sorghum bicolor (L.) Moench by high-throughput sequencing analysis. Front. Plant Sci. 6, 506 (2015).

25. Jagannadham, P. T. K., Muthusamy, S. K. \& Chidambaranathan, P. Micromics: a novel approach to understand the molecular mechanisms in plant stress tolerance. In Recent Approaches in Omics for Plant Resilience to Climate Change Vol. 22 (ed. Wani, S. H.) (Springer, Cham, 2019). https://doi.org/10.1007/978-3-030-21687-0_5.

26. Munns, R. et al. Wheat grain yield on saline soils is improved by an ancestral $\mathrm{Na}^{+}$transporter gene. Nat. Biotechnol. 30, 360-364 (2012).

27. Huang, Q. et al. TaNAC29, a NAC transcription factor from wheat, enhances salt and drought tolerance in transgenic Arabidopsis. BMC Plant Biol. 15, 1-15 (2015).

28. Liu, S. et al. A wheat SIMILAR TO RCD-ONE gene enhances seedling growth and abiotic stress resistance by modulating redox homeostasis and maintaining genomic integrity. Plant Cell 26, 164-180 (2014).

29. Zhao, Y. et al. A wheat allene oxide cyclase gene enhances salinity tolerance via jasmonate signaling. Plant Physiol. 164, 1068-1076 (2014).

30. Li, C. et al. TaCHP: a wheat zinc finger protein gene down-regulated by abscisic acid and salinity stress plays a positive role in stress tolerance. Plant Physiol. 154, 211-221 (2010).

31. Gao, Z. et al. Overexpressing a putative aquaporin gene from wheat, TaNIP, enhances salt tolerance in transgenic arabidopsis. Plant Cell Physiol. 51, 767-775 (2010).

32. Dong, W. et al. Wheat oxophytodienoate reductase gene TaOPR1 confers salinity tolerance via enhancement of abscisic acid signaling and reactive oxygen species scavenging. Plant Physiol. 161, 1217-1228 (2013).

33. Muthusamy, S. K., Dalal, M., Chinnusamy, V. \& Bansal, K. C. Differential regulation of genes coding for organelle and cytosolic ClpATPases under biotic and abiotic stresses in wheat. Front. Plant Sci. 7, 929 (2016).

34. Zhou, W. et al. Overexpression of TaSTRG gene improves salt and drought tolerance in rice. J. Plant Physiol. 166, 1660-1671 (2009).

35. Munns, R., Wallace, P. A., Teakle, N. L. \& Colmer, T. D. Measuring soluble ion concentrations $\left(\mathrm{Na}^{(+)}, \mathrm{K}^{(+)}, \mathrm{Cl}^{(-)}\right)$in salt-treated plants. Methods Mol. Biol. 639, 371-382 (2010).

36. Ke, Q. et al. Melatonin mitigates salt stress in wheat seedlings by modulating polyamine metabolism. Front. Plant Sci. 9, 914 (2018).

37. De Souza Miranda, R. et al. Integrative control between proton pumps and SOS1 antiporters in roots is crucial for maintaining low $\mathrm{Na}^{+}$accumulation and salt tolerance in ammonium-supplied Sorghum bicolor. Plant Cell Physiol. 58, 522-536 (2017).

38. Asadi, M., Golkar, P., Naghavi, H. \& Nakhoda, B. Assessment of salinity tolerance of different promising lines of bread wheat (Triticum aestivum L.). Adv. Appl. Sci. Res. 3, 1117-1121 (2012).

39. Kumar, K., Kumar, M., Kim, S.-R., Ryu, H. \& Cho, Y.-G. Insights into genomics of salt stress response in rice. Rice 6, 27 (2013).

40. Mittal, D., Sharma, N., Sharma, V., Sopory, S. K. \& Sanan-Mishra, N. Role of microRNAs in rice plant under salt stress. Ann. Appl. Biol. 168, 2-18 (2016).

41. Horton, P. et al. WoLF PSORT: protein localization predictor. Nucleic Acids Res. 35, W585-W587 (2007).

42. Emanuelsson, O., Brunak, S., von Heijne, G. \& Nielsen, H. Locating proteins in the cell using TargetP, SignalP and related tools. Nat. Protoc. 2, 953-971 (2007).

43. Sievers, F. et al. Fast, scalable generation of high-quality protein multiple sequence alignments using Clustal Omega. Mol. Syst. Biol. 7, 539 (2011).

44. Hruz, T. et al. Genevestigator V3: a reference expression database for the meta-analysis of transcriptomes. Adv. Bioinform. 2008, 1-5 (2008).

45. Ramírez-González, R. H. et al. The transcriptional landscape of polyploid wheat. Science 361, eaar6089 (2018).

46. Mott, I. W. \& Wang, R.R.-C. Comparative transcriptome analysis of salt-tolerant wheat germplasm lines using wheat genome arrays. Plant Sci. 173, 327-339 (2007).

47. You, F. F. M. et al. BatchPrimer3: a high throughput web application for PCR and sequencing primer design. BMC Bioinform. 9, $253(2008)$.

48. Sharma, P. et al. Development and validation of microsatellite markers for Karnal bunt (Tilletia indica) and loose smut (Ustilago segetum tritici) of wheat from related fungal species. J. Phytopathol. 166, 729-738 (2018).

49. Munns, R. \& Tester, M. Mechanisms of Salinity Tolerance. https://doi.org/10.1146/annurev.arplant.59.032607.092911 (2008). doi: https://doi.org/10.1146/ANNUREV.ARPLANT.59.032607.092911.

50. Chinnusamy, V. \& Zhu, J.-K. Epigenetic regulation of stress responses in plants. Curr. Opin. Plant Biol. 12, 133-139 (2009).

51. Mba, C., Guimaraes, E. P. \& Ghosh, K. Re-orienting crop improvement for the changing climatic conditions of the 21 st century. Agric. Food Secur. 1, 7 (2012).

52. Butcher, K., Wick, A. F., Desutter, T., Chatterjee, A. \& Harmon, J. Soil salinity: a threat to global food security. Agron. J. 108, 2189-2200 (2016).

53. Reddy, I. N. B. L., Kim, B.-K., Yoon, I.-S., Kim, K.-H. \& Kwon, T.-R. Salt tolerance in rice: focus on mechanisms and approaches. Rice Sci. 24, 123-144 (2017).

54. Thao, N. P. \& Tran, L.-S.P. Enhancement of plant productivity in the post-genomics era. Curr. Genomics 17, 295-296 (2016).

55. Kumar, S., Muthusamy, S. K., Mishra, C. N., Gupta, V. \& Venkatesh, K. In Advanced Molecular Plant Breeding (ed. Bharadwaj, D. N.) 275-296 (Springer, Berlin, 2018). https://doi.org/10.1201/b22473-8.

56. Shahzad, A., Ahmad, M., Iqbal, M., Ahmed, I. \& Ali, G. M. Evaluation of wheat landrace genotypes for salinity tolerance at vegetative stage by using morphological and molecular markers. Genet. Mol. Res. 11, 679-692 (2012).

57. Nevo, E. \& Chen, G. Drought and salt tolerances in wild relatives for wheat and barley improvement. Plant Cell Environ. 33, 670-685 (2010).

58. Chinnusamy, V. \& Zhu, J.-K. Plant salt tolerance. In Plant Responses to Abiotic Stress (eds Hirt, H. \& Shinozaki, K.) 241-270 (Springer, Berlin, 2004). https://doi.org/10.1007/978-3-540-39402-0_10.

59. Chattopadhyay, K. et al. Diversity and validation of microsatellite markers in Saltol QTL region in contrasting rice genotypes for salt tolerance at the early vegetative stage. Aust. J. Crop Sci. 8, 356-362 (2014). 
60. Chen, M., Tan, Z., Zeng, G. \& Peng, J. Comprehensive analysis of simple sequence repeats in Pre-miRNAs. Mol. Biol. Evol. 27, 2227-2232 (2010).

61. Ma, K. H. et al. Development of SSR markers for studies of diversity in the genus Fagopyrum. Theor. Appl. Genet. 119, 1247-1254 (2009).

62. Konishi, T. et al. Development and characterization of microsatellite markers for common buckwheat. Breed. Sci. 56, 277-285 (2006).

63. Fernandez, G. C. J. Effective selection criteria for assessing stress tolerance. In Adaptation of Food Crops to Temperature and Water Stress 257-270 (1992).

64. Ouyang, S. et al. The TIGR rice genome annotation resource: improvements and new features. Nucleic Acids Res. 35, D883-D887 (2007).

65. Dai, X. \& Zhao, P. X. psRNATarget: a plant small RNA target analysis server. Nucleic Acids Res. 39, W155-W159 (2011).

66. Sun, F. et al. Whole-genome discovery of miRNAs and their targets in wheat (Triticum aestivum L.). BMC Plant Biol. 14, 142 (2014).

67. Borrill, P., Ramirez-Gonzalez, R. \& Uauy, C. expVIP: a customisable RNA-seq data analysis and visualisation platform. Plant Physiol. https://doi.org/10.1104/pp.15.01667 (2016).

68. Iquebal, M. A. et al. RNAseq analysis reveals drought-responsive molecular pathways with candidate genes and putative molecular markers in root tissue of wheat. Sci. Rep. 9, 1-18 (2019).

69. Lenka, S. K. et al. Heterologous expression of rice RNA-binding glycine-rich (RBG) gene OsRBGD3 in transgenic Arabidopsis thaliana confers cold stress tolerance. Funct. Plant Biol. 46, 482-491 (2019).

70. Murray, M. G. \& Thompson, W. F. Rapid isolation of high molecular weight plant DNA. Nucleic Acids Res. 8, 4321-4326 (1980).

71. Botstein, D., White, R. L., Skolnick, M. \& Davis, R. W. Construction of a genetic linkage map in man using restriction fragment length polymorphisms. Am. J. Hum. Genet. 32, 314 (1980).

72. Perrier, X., Flori, A. \& Bonnot, F. Data analysis methods. In Genetic Diversity of Cultivated Tropical Plants (eds Hamon, P. et al.) (Enfield Science Publishers, New Hampshire, 2003).

\section{Acknowledgements}

The Authors gratefully acknowledge the financial support provided by Indian Council of Agricultural Research, New Delhi (F. No. 64-1-17, DWR/RP/10-5.3, Edn./34/2/2015). The authors acknowledge to Germplasm Resource Unit of ICAR-Indian Institute of Wheat and Barley Research, Karnal and Director, ICAR-Central Soil Salinity Research Institute, Karnal for supply of seed material. This is IIWBR Paper Contribution No. 135/162.

\section{Author contributions}

P.S. conceived the idea and designed the experiments. S.K.M. performed bioinformatics and insilico expression analysis. G., and P.S. performed phenotyping, genotyping and qPCR gene expression analysis. S.K.M. and P.S. drafted the manuscript. P.S. and G.P.S. edited the manuscript. All the authors have read and approved the final manuscript.

\section{Competing interests}

The authors declare no competing interests.

\section{Additional information}

Supplementary Information The online version contains supplementary material availlable at https://doi. org/10.1038/s41598-021-81698-3.

Correspondence and requests for materials should be addressed to P.S.

Reprints and permissions information is available at www.nature.com/reprints.

Publisher's note Springer Nature remains neutral with regard to jurisdictional claims in published maps and institutional affiliations.

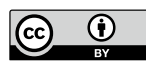

Open Access This article is licensed under a Creative Commons Attribution 4.0 International License, which permits use, sharing, adaptation, distribution and reproduction in any medium or format, as long as you give appropriate credit to the original author(s) and the source, provide a link to the Creative Commons licence, and indicate if changes were made. The images or other third party material in this article are included in the article's Creative Commons licence, unless indicated otherwise in a credit line to the material. If material is not included in the article's Creative Commons licence and your intended use is not permitted by statutory regulation or exceeds the permitted use, you will need to obtain permission directly from the copyright holder. To view a copy of this licence, visit http://creativecommons.org/licenses/by/4.0/.

(c) The Author(s) 2021 